\title{
SLEEP DISTURBANCES AND FATIGUE AMONG WOMEN IN POSTNATAL PERIOD
}

\author{
Prof. Dr. Nadia Mohamed Fahmiy, Assistant prof. Mona Abd-EISabour Hassan, \\ Assistant prof. Nagat Salah Salama, Al- Shimaa Mohsen Ahmed El-Morsey. \\ Prof of Maternal\& New born Health Nursing, Faculty of Nursing-Ain Shams \\ University, Assistant Prof of Family and Community Health Nursing Nursing, Faculty \\ of Nursing - Port-said University, Assistant Prof of Maternity, Obstetric and \\ Gynecological Nursing, Faculty of Nursing - Port-said University, BSc. Nursing -
} Assuit University 2008.

\begin{abstract}
Background: Sleep in the postpartum period is a concern due to robust associations with wake disturbance, fatigue, and depression. Objectives: The aim of this study was to assess sleep disturbances and fatigue among women in postnatal period. Subject and Methods: Design a descriptive study design was utilized in this study. Settings the study was carried out in six health centers in Port-Said city namely (El-Manakh, Bank El-Escan, El-Arab, El-Kuwait, Port-Fouad (2), and Omar Ebn-ElKhatab). Sample a Purposive sample was followed in the present study. The study subjects consisted of 322 postpartum women recruited from postpartum outpatient clinics in the above mentioned settings. A Structured interviewed schedule sheet, the Global Sleep Assessment Questionnaire (GSAQ), and the Multidimensional Fatigue Symptom Inventory Short (MFSI_SF). Results: The study's results indicated that (69.6\%) had high sleep disturbance, and (93.8\%) had high fatigue. There was statistical significant relation between sleep disturbance and women's residence $(\mathrm{p}=0.007)$, women's mode of delivery $(\mathrm{p}=0.015)$, and women with problems after delivery $(\mathrm{p}=0.019)$. There were statistically significant relationship between fatigue and crowding index $(\mathrm{p}=0.009)$, women's residence $(\mathrm{p}=0.021)$, complication after delivery $(p=0.009)$, hospital's stay after delivery $(p=0.018)$, and receiving help for caring the baby from their sisters $(\mathrm{p}=0.042)$. Conclusion: It was concluded that, the great majority of the studied women had postnatal fatigue, and about more than twothirds of them had sleep disturbance. Factors that were increased these problems including living with extended family and high crowding index. Receiving postnatal instructions seems to decrease both sleep and fatigue problems; both sleep and fatigue were decreased with staying one day only at the hospital. While help giving at home from women's sisters was decreasing women's sleep disturbances and fatigue compared with help from husband. There was a highly statistically significant positive correlation between sleep disturbance and fatigue. Recommendations: It was recommended that awareness program for women and nurses about caring for postnatal period and who are at risk of developing postnatal fatigue and sleep disturbances, and help them to cope with the difficulties encountered.
\end{abstract}

Key words: Postpartum period, sleep disturbances, fatigue. 


\section{INTRODUCTION}

The first three months after delivery, are recognized as the most vulnerable emotional period for mothers, as insecurity about infant care, the constant demands associated with caring for the baby, and sleep deprivation and minimal social support create the potential for frequent and dramatic mood changes (Ward et al., 2016). Sleep is vital, allowing the body to rest, replenish resources in the brain and body (Kempler et al., 2012). Changes in sleep patterns during this period affects health and functions of mothers and creates many problems not only for them but also for their babies. One of the most important side effects of inadequate quality of sleep include hormonal shifts and the beginning of new and unfamiliar childbearing tasks, can cause prim parous mothers to experience stress and fatigue (Ashrafinia et al., 2015).

Fatigue is an "awareness of a decreased capacity for physical and/ or mental activity due to an imbalance in the availability, utilization, and/or restoration of resources needed to perform activity" (White et al., 2015). Fatigue affects negatively not only the performances and life qualities of women, but also life quality of mothers' families (Kilic et al., 2015).

Fatigue experienced by mothers on the first 2 days of postpartum was greater compared to other postpartum periods (Kilic et al., 2015). This phenomenon often begins immediately after delivery and reaches its maximum severity within 36 hours. In contrast to the belief that it is a temporary experience, postpartum fatigue can last for a prolonged period after delivery (Ashrafinia et al., 2015). It would be very important to properly control fatigue during the initial period following childbirth, including the period of hospitalization (Mohammed S., 2010).

Sleep disturbance in the early postpartum period is highly prevalent, varying from $70.5 \%$ to $72.3 \%$ (Kuo, et al., 2014). Sleep disturbance among the Egyptian women according to a study conducted at the post-partum ward at Ain Shams Maternity Hospital, Cairo, Egypt is $45.2 \%$ and fatigue among the Egyptian women was 51\% (Mohamed et al., 2012). The number of problems postpartum mothers with sleep disturbance has increased gradually (Sung-Hee, 2004). The period of hospitalization following childbirth is too short for nurses to properly monitor and control postpartum fatigue and sleep disturbances. 
The nurses play an important role in improving woman`s health and health care (Rychnovsky\& Hunter, 2009). During the immediate postpartum period as well as the early days postpartum, care and support must be equally balanced among three critical areas: assessment, monitoring, and support of the mother`s physiological and emotional adaption following birth; and support of the developing mother-infant and family relationships (McCann, 2008). While taking care of postpartum mothers after childbirth, nurses are in the best position to carefully observe and evaluate their levels of fatigue and sleep disturbances (Shih-Yu\&Lee, 2007).

\section{AIM OF STUDY:}

The aim of this study was to assess sleep disturbances and fatigue among women in postnatal period.

\section{Research Questions:}

To achieve the aim of this study the following questions should be answered:

1. What is the prevalence of sleep disturbances and fatigue among women in the postnatal period in Port Said City?

2. What are the factors leading to sleep disturbances and fatigue on the women in the postnatal period?

3. What are the effects of the sleep disturbances and fatigue on the women health in the postnatal period?

\section{SUBJECT AND METHODS:}

Research design: A descriptive purposive study was utilized in the present study to assess sleep disturbances and fatigue among women in postnatal period. Sample Size: The sample size was determined using the following equation

$\mathrm{Z} 2$

Sample size $(\mathrm{n})=----------\quad P(100-P)$

D2.

Study setting: The present study was conducted in outpatient clinic in six health centers in Port-Said city namely El-Manakh, Bank El-Escan, El-Arab, El-Kuwait, Port-Fouad (2), Omar Ebn-ElKhatab. Subjects: The sample consisted of 322 postpartum women recruited from postpartum outpatient clinics during immunizing their babies at the study setting. 


\section{Tools for data collection:}

\section{A structured Interviewed schedule sheet:}

This form was developed and constructed by the researcher after reviewing the related literature for the purpose of data collection to achieve the aims of the study. It entailed information related to the following:

$>\quad$ Women's socio-demographic characteristics as woman`s age, level of education, occupation, residence, and crowding index (person/room)

Women's post-natal data: This part included information about early postnatal period during hospital stay; it woman postnatal visit such as timing of the visit, instructions received about post- included the mode of delivery and any associated problems, period of hospital stay, the natal care, and the person who helped woman at home for care of baby.

\section{The Modified Global Sleep Assessment Questionnaire (GSAQ):-}

This scale was developed by Roth et al., (2002) and translated by Mohamed S., (2010). It used to evaluate sleep pattern and causes of sleep disturbances among postnatal women. It consists of 15 items.

\section{Scoring System:}

The items of the scale were classified into six principal components according to Unger et al., (2004). These are insomnialhypersomnia (1 item), non-restorative sleep (3 items), sleep schedule disorder (5 items), excessive daytime somnolence (1 items), sleep apnea (2 items), and restlessness ( 3 items).Responses are measured on a 4-point Likert scale where the highest score indicates the highest level of sleep disturbances. The four categories for scoring system are: never $=1$, sometimes $=2$, usually $=3$, and always $=4$. For individual item analysis, the scale was dichotomized by grouping never with sometimes, and usually with always. Then for quantitative analysis, the responses never, sometimes, usually, and always were respectively given scores 1 to 4. The sum score of each component was calculated and its mean and standard deviations were computed by dividing by the number of items. Then, the total of each component and of the scale was dichotomized into low if the mean was less than 2 and high if 2 or higher. 


\section{The Multidimensional Fatigue Symptom Inventory Short Form (MFSI_SF)}

This scale was developed by Stein et al., (2004), and translated by Mohamed S., (2010). It used to evaluate fatigue symptoms among postnatal women. It consists of 30 items.

\section{Scoring System:}

The items of the scale were classified into its six principal components according to Reeves et al., (2003). These are emotional (6 items), general (6 items), mental (6 items), physical (6 items), and vigor (6 items). Responses are measured on a 5-point Likert scale where the highest score indicates the highest level of fatigue symptoms. The five categories for scoring system are Not at all=1, A little=2, Moderately =3, Quite a bit=4, Extremely=5. For individual item analysis, the scale was dichotomized by grouping not at all with a little and moderately, and quite a bit with extremely. Then, for quantitative analysis, the responses not at all, a little, moderately, quite a bit, and extremely were respectively given scores 1 to 5 . The sum score of each component was calculated and its mean and standard deviations were computed by dividing by the number of items. Then, the total of each component and of the scale was dichotomized into low if the mean was less than 3 and high if 3 or higher.

Tools Validity: The first tool was ascertained by a jury consisting of 5 experts in nursing field.

Reliability: Cronbach alpha coefficient will calculated to assess the reliability of the developed tool through their internal consistency. The pilot study was carried out on $10 \%$ (33) of women in postnatal period going to the clinic excluded from the sample to test applicability of the tool then necessary modification will be done according to the results of pilot study.

- A pilot study was carried out over a period of two months. It was conducted on $10 \%$ of total sample size involving women to evaluate the content validity, time required to fill each tool and feasibility of tools of the study. Necessary modifications were carried out as revealed from the pilot study. 


\section{Filed Work:}

- The above mentioned setting was selected randomly from 12 health care centers in Port Said city during the period from the first of December 2015 to end of April 2016.

- Data will be collected by the researcher from 9 am -12 pm from pre mentioned setting.

- Women who come to immunized their baby or who attended to family planning clinic will be interviewed by the researcher herself before or after the enter the clinic to collect the necessary data using pre mentioned tools.

- The researcher will briefly explained the nature and the aim of the study to the approached ones who met the criteria for inclusion in the sample. Each subject will be interviewed individually. The pre mentioned tools takes about 15 mints.

\section{Ethical considerations:}

The following research ethics was considered \& maintained during the study :

1. Women were informed that they are allowed to choose participate or not in the study and have the right to withdraw from the study in any time .

2. The researcher will clarify the aim of the study to the women.

3. The researcher will assure maintain anonymity and confidentiality of the subject data and all data is confidential used for research purpose only.

4. Oral consent was taken from each woman in order to participate in the study.

\section{Administrative design:}

An official letter from the dean of the faculty of nursing will be sent to the director of primary health care centers. The director of each clinic will be contacted and informed in order to obtain permission to include the women`s on the present research.

\section{Statistical analysis of data:}

Data were coded and transferred into specially designed formats for data entry then data were analyzed and computed. The collected data were organized, categorized, tabulated in tables using numbers and percentage, mean percentage and standard deviation. Chi-square $\left(\chi^{2}\right)$ test was used to test the associations among the under studied 
qualitative variable, the statistical package for social sciences (SPSS version 16.0) was used for statistical analysis. Statistical significant was considered at P-value $<0.05$.

\section{RESULTS:}

Distribution of women's total sleep disturbance assessment score among studied women after delivery in table 1. Reveals that, the most frequent sleep disturbance was that of insomnia $100.0 \%$, followed by $99.1 \%$ with excessive daytime somnolence. On the other hand, the least sleep disturbance was that of sleep schedule disorder (1.6\%). Overall, more than two-third (69.6\%) had high sleep disturbance, with a mean (SD) score $2.12 \pm 0.32$ from a maximum of 3 .

Distribution of women's total sleep disturbance assessment score among studied women after delivery in table 2. Indicates that, the most common type of high fatigue among studied women was physical type (98.8\%), followed by general type (91.9\%), then emotional type $(91.0 \%)$. Overall, $(93.8 \%)$ of women had high fatigue.

Table (3): Factors affecting sleep disturbances on the women in the postnatal period. It Illustrates that, there were statistically significant relationship between sleep disturbances and crowding index $(\mathrm{p}=0.007)$. Monte Carlo for Chi square test and Fisher Exact for Chi square test is used. Also it demonstrates that, there were statistical significant associations between sleep disturbance and women's mode of delivery ( $\mathrm{p}=0.015)$, and women who were complaining from constipation $(\mathrm{p}=0.013)$. The sleep disturbance was higher among women who had cesarean section (88.4\%), and $79.8 \%$ complaining from constipation.

Table (4): Factors affecting fatigue on the women in the postnatal period. Monte Carlo for Chi square test and Fisher Exact for Chi square test is used. It illustrates that, there were statistically significant relationship between fatigue and crowding index $(\mathrm{p}=0.009)$, women's residence $(\mathrm{p}=0.021)$. Also it demonstrates that, there were statistical associations between fatigue and complication after delivery $(\mathrm{p}=0.009)$, and women who complain from constipation $(\mathrm{p}=0.002)$. It is noticed from the table that, the fatigue was higher among women who had constipation $(77.8 \%)$. 
Table (5): Relationship between fatigue with hospital's stay and receiving help after delivery. Monte Carlo for Chi square test and Fisher Exact for Chi square test is used. It demonstrates that, there was statistical significant association between fatigue and hospital's stay after delivery $(\mathrm{p}=0.018)$. It is noticed from the table that, the fatigue was higher among women who were stayed only one day in the hospital after delivery $(64.2 \%)$. About concerning the relation between fatigue and receiving postnatal help, It is noticed from the table that, there were statistical significance relation between fatigue and receiving help for caring the baby from their sisters $(\mathrm{p}=0.042)$, others such relatives $(\mathrm{p}=0.050)$. Table (6) shows a statistically significant relation between women's sleep disturbance and fatigue problem $(\mathrm{p}<0.001)$. It is evident that most women with low sleep disturbance problem had low fatigue problem (17.3\%). On the other hand, most women with high sleep disturbance had high fatigue problem $(98.7 \%)$.

Table (1): Distribution of women's total sleep disturbance assessment score among studied women after delivery $(n=322)$

\begin{tabular}{||c||c|c||c|c||c||}
\hline \multirow{2}{*}{ Type of sleep disturbance } & \multicolumn{2}{|c|}{ Low $<2$} & \multicolumn{2}{c||}{ High $\geq \mathbf{2}$} & \multirow{2}{*}{} \\
\cline { 2 - 5 } & $\mathbf{N o}$ & $\mathbf{\%}$ & No. & $\%$ & mean (SD) \\
\hline Insomnia/hypersomnia & 0 & 0.0 & 322 & 100.0 & $3.38 \pm 0.67$ \\
\hline Excessive daytime somnolence & 3 & 0.9 & 319 & 99.1 & $3.17 \pm 0.68$ \\
\hline \hline Restlessness & 7 & 2.2 & 315 & 97.8 & $2.93 \pm 0.49$ \\
\hline \hline Non-restorative sleep & 26 & 8.1 & 296 & 91.9 & $2.61 \pm 0.54$ \\
\hline Sleep apnea & 230 & 71.4 & 92 & 28.6 & $1.50 \pm 0.57$ \\
\hline \hline Sleep schedule disorder & 317 & 98.4 & 5 & 1.6 & $1.14 \pm 0.26$ \\
\hline \hline Overall & $\mathbf{9 8}$ & $\mathbf{3 0 . 4}$ & $\mathbf{2 2 4}$ & $\mathbf{6 9 . 6}$ & $\mathbf{2 . 1 2} \pm \mathbf{0 . 3 2}$ \\
\hline
\end{tabular}


Table (2): Distribution of women's total fatigue assessment score among studied women after delivery $(n=322)$

\begin{tabular}{|c|c|c|c|c|c|}
\hline \multirow[b]{2}{*}{ Total fatigue assessment } & \multicolumn{2}{|c|}{$\bar{L}$ Low $<3$} & \multicolumn{2}{|c|}{ High $\geq 3$} & \multirow[b]{2}{*}{ Mean \pm SD } \\
\hline & No & $\%$ & No & $\%$ & \\
\hline Physical & 4 & 1.2 & 318 & 98.8 & $4.53 \pm 0.54$ \\
\hline General & 26 & 8.1 & 296 & 91.9 & $3.95 \pm 0.64$ \\
\hline Emotional & 29 & 9.0 & 293 & 91.0 & $3.86 \pm 0.65$ \\
\hline Mental & 36 & 11.2 & 286 & 88.8 & $3.87 \pm 0.69$ \\
\hline Vigor & 43 & 13.4 & 279 & 86.6 & $3.35 \pm 0.43$ \\
\hline Overall & 20 & 6.2 & 302 & 93.8 & $3.91 \pm 0.51$ \\
\hline
\end{tabular}

Table (3): Factors affecting sleep disturbances on the women in the postnatal period $(n=322)$ :

\begin{tabular}{|c|c|c|c|c|c|c|}
\hline Socio-demographic characteristic & $\begin{array}{c}\text { Low } \\
<2\end{array}$ & $\%$ & $\begin{array}{c}\text { High } \\
\geq 2\end{array}$ & $\%$ & $\begin{array}{c}\text { Test of } \\
\text { sig. }\end{array}$ & p-value \\
\hline \multicolumn{7}{|l|}{ Residence } \\
\hline Separate & 61 & 62.2 & 172 & 172 & \multirow[b]{2}{*}{7.207} & \multirow[b]{2}{*}{$0.007 *$} \\
\hline With the family & 37 & 37.8 & 52 & 52 & & \\
\hline \multicolumn{7}{|l|}{ Type of delivery } \\
\hline Vaginal & 9 & 9.2 & 5 & 2.2 & \multirow{3}{*}{8.428} & \multirow{3}{*}{$0.015^{*}$} \\
\hline Cesarean & 78 & 79.6 & 198 & 88.4 & & \\
\hline Vaginal with episiotomy & 11 & 11.2 & 21 & 9.4 & & \\
\hline \multicolumn{7}{|l|}{ problems after delivery } \\
\hline Pain from episiotomy & 11 & 12.8 & 22 & 10.3 & 0.378 & 0.539 \\
\hline Constipation & 57 & 66.3 & 170 & 79.8 & 6.137 & $0.013 *$ \\
\hline Piles & 25 & 29.1 & 36.2 & 36.2 & 1.366 & 0.242 \\
\hline
\end{tabular}

*Statistical significant at $\mathrm{p}$-value $<0.05$ 
Table (4): Factors affecting fatigue on the women in the postnatal period $(n=322)$ :

\begin{tabular}{|c|c|c|c|c|c|c|}
\hline & \multicolumn{2}{|c|}{$\begin{array}{l}\text { Low }<3 \\
(\mathrm{n}=20)\end{array}$} & \multicolumn{2}{|c|}{$\begin{array}{r}\text { High } \geq 3 \\
(n=302)\end{array}$} & \multirow{2}{*}{$\begin{array}{l}\text { Test of } \\
\text { sig. }\end{array}$} & \multirow[t]{2}{*}{ p-value } \\
\hline & No. & $\%$ & No. & $\%$ & & \\
\hline \multicolumn{7}{|l|}{ Crowding index } \\
\hline Severely Crowded & $\mathbf{0}$ & 0.0 & 24 & 7.9 & \multirow{3}{*}{$8.734 *$} & \multirow{3}{*}{$0.009 *$} \\
\hline Crowded & $\mathbf{0}$ & $\mathbf{0 . 0}$ & 67 & 22.2 & & \\
\hline Not Crowded & 20 & $\begin{array}{c}100 . \\
0\end{array}$ & 211 & 69.9 & & \\
\hline \multicolumn{7}{|l|}{ Residence } \\
\hline Nuclear (Private) & 10 & $\mathbf{5 0 . 0}$ & 223 & 73.8 & \multirow{2}{*}{5.331} & \multirow{2}{*}{$0.021 *$} \\
\hline (Extended)With the family & 10 & $\mathbf{5 0 . 0}$ & 79 & 26.2 & & \\
\hline \multicolumn{7}{|l|}{ Problems after delivery } \\
\hline Pain from episiotomy & 1 & 6.7 & 32 & 11.3 & 0.307 & FEp $=1.0$ \\
\hline Constipation & 6 & 40.0 & 221 & 77.8 & 11.145 & $\begin{array}{c}\text { FEp }=0.002 \\
*\end{array}$ \\
\hline Piles & 4 & 26.7 & 98 & 34.5 & 0.390 & 0.532 \\
\hline
\end{tabular}

*Statistical significant at $\mathrm{p}$-value $<0.05$

Table (5): Relationship between fatigue with hospital's stay and receiving help after delivery $(n=322)$

\begin{tabular}{|c|c|c|c|c|c|c|}
\hline & \multicolumn{2}{|c|}{$\begin{array}{c}\text { Low }<3 \\
(n=20)\end{array}$} & \multicolumn{2}{|c|}{$\begin{array}{l}\text { High } \geq 3 \\
(n=302)\end{array}$} & \multirow{2}{*}{$\begin{array}{l}\text { Test of } \\
\text { sig. }\end{array}$} & \multirow{2}{*}{ p-value } \\
\hline & No. & $\%$ & No. & $\%$ & & \\
\hline \multicolumn{7}{|l|}{ Hospital stay in days } \\
\hline 1 & 7 & 35.0 & 194 & 64.2 & \multirow{3}{*}{$8.087 *$} & \multirow{3}{*}{$\mathrm{MCp}=0.018^{*}$} \\
\hline 2 & 13 & 65.0 & 102 & 33.8 & & \\
\hline$\geq 3$ & 0 & 0.0 & 6 & 2.0 & & \\
\hline \multicolumn{7}{|c|}{ Receiving help for care the baby $(n=126)$} \\
\hline No help & 11 & 55.0 & 155 & 38.1 & 2.255 & 0.133 \\
\hline Help form mother & 8 & 72.7 & 63 & 54.8 & 1.314 & $\mathrm{FEp}=0.346$ \\
\hline Help form husband & 1 & 9.1 & 17 & 14.8 & 0.266 & $\mathrm{FEp}=1.0$ \\
\hline Help form sister & 4 & 36.4 & 13 & 11.3 & 5.402 & $\begin{array}{c}\mathrm{FEp}=0.042 \\
*\end{array}$ \\
\hline Help form mother in-low & 0 & 0.0 & 27 & 23.5 & 3.287 & FEp $=0.119$ \\
\hline Help for Other: relative & 3 & 27.3 & 11 & 9.5 & 8.932 & $\begin{array}{c}\mathrm{MCp}=0.05 \\
0^{*}\end{array}$ \\
\hline
\end{tabular}


Table (6): Relation between women's sleep disturbance and fatigue

\begin{tabular}{|c|c|c|c|c|c|c|}
\hline \multirow{3}{*}{ Overall fatigue } & \multicolumn{4}{|c|}{ Overall sleep disturbance } & \multirow{3}{*}{$\chi 2$} & \multirow{3}{*}{ p-value } \\
\hline & \multicolumn{2}{|c|}{ Low $<2$} & \multicolumn{2}{|c|}{ High $\geq 2$} & & \\
\hline & No & $\%$ & No & $\%$ & & \\
\hline Low & 17 & 17.3 & 3 & 1.3 & & \\
\hline High & 81 & 82.7 & 221 & 98.7 & & \\
\hline
\end{tabular}

$x 2, p: x 2$ and $p$ values for Chi square test for comparing between the two groups

*: Statistically significant at $\mathrm{p} \leq 0.05$

\section{DISCUSSION:}

The study was carried out on 322 women. As show, in the present study more than two-thirds of the studied women had sleep disturbances after delivery, Similarly, Ko et al., (2014) in a Taiwanese study found that great majority of mothers experienced some sleep problems and were suspected of being at high risk of poor sleep quality. This result was in the opposite way with Mohamed (2010) who carried out study on sleep disturbances and fatigue at AL Nor Specialist Hospital-Makka, revealed that only one-fifth of the studied women have sleep disturbance. These wide differences in the prevalence of postnatal sleep disorders among various studies might be attributed to that the present study consisted of primparous and multiparous with vaginal delivery or cesarean section delivery, while Mohamed's study selected normal prim parous women only.

One factor that has been more influencing the duration and severity of women's physical and psychological symptoms following childbirth is the mode of birth (Rowlands\& Redshaw., 2012). These agree with Mousav et al., (2013) who indicate that symptoms such as fatigue, headache, lack of sleep and other conditions have reported higher in women who delivered by cesarean section than those who underwent vaginal delivery (VD). The current study findings illustrated that, most of the women delivered by cesarean section had sleep disturbances. On the same line, Hall et al., (2012) In Taiwanese, Swedish, and American samples, founded that fatigue and sleep deprivation have been associated with increased risk of caesarean sections. 
Concerning the effect of help given to women on sleep and fatigue problems, the present study showed a positive effect among women who got help from their sisters, whereas the sleep and fatigue problems was higher among those who got help from their husbands in compared with getting help from there sisters. These findings might be attributed to lack of trust in husband's ability to care for the newborn. Thus, the parturient woman would be under more stress when the husband, compared to the sisters who is usually well trained in this matter, provides the help.

According to the present study results, great majority of the present studied women had postnatal fatigue. An important finding was that the frequency of physical fatigue was higher than emotional fatigue, respectively. This indicates that the problem of postnatal fatigue is due to tiredness and exhaustion. Just the opposite study of Kammerer et al., (2009), who demonstrated that postnatal fatigue was one of the best discriminating symptoms of postnatal depression, which confirms it's emotional and mental rather than physical elements.

One factor that has consistently identified as influencing the duration and severity of women is physical and psychological symptoms following childbirth is the mode of birth (Rowlands\& Redshaw., 2012). As well the study of (Kilic et al., 2015) were conducted on 383 postpartum women, founded that the fatigue levels of the postpartum women who had vaginal birth were lower compared to those giving caesarean section, their energies were higher than the postpartum women who gave caesarean section.

Studies have reported that women in postpartum period complain of numerous physical problems (Huang K et al. 2011). As well, Rezaei et al reported that fatigue is the most prevalent postpartum physical health problems experienced by more than half of mothers (Rezaei et al., 2016). In contrast with the present study, Cheng et al. (2008) studied the postnatal physical and psychological problems among women in Virginia, USA, but did not report any relations between them.

As regards hospital stay and its relation with postnatal fatigue, the present study showed an inverse relation. Thus, the percentages of women with fatigue problem decreased with increasing length of hospital stay. This explained by the fact that women with longer stay have more chance to get help and support during this period. In the agreement with that Karbandi et al., (2016) founded that women who are 
discharged from the hospital shortly after delivery and are transferred to the home spending their 1st days and weeks without care most experience some small or big problems such as fatigue, back pain, discomfort caused by cesarean wound or episiotomy.

Aigboje\& Osa-Afiana, (2013) reported that, sleep deprived persons feel tired, irritable and confused even though they are able to do well on motivated tasks with their usual strength and skill. The present study revealed a statistically significant positive correlation between the sleep disturbances and fatigue at the first 8 weeks after delivery. This means that fatigue might be increased by sleep deprivation, or reciprocally the excess fatigue leads to sleep disturbances. In line with this, Rychnovsky J. (2011) in a study in Naval Medical Center San Diego examined the relation between sleep characteristics and postpartum fatigue the first 6-8 weeks. They founded that fatigue correlated with fragmented sleep, sleep quality, sleep disturbance, and sleep effectiveness.

In agreement with the foregoing present findings, Rychnovsky \& Hunter, (2009); McBean and Montgomery-Downs., (2015) in their study examined the relation between sleep characteristics and postpartum fatigue. They demonstrated that higher levels of fatigue are associated with more disturbed sleep during the postpartum period. However, fatigue levels also vary over the 24-hr day in a pattern dictated by the endogenous circadian rhythm.

According to the present study findings, there were relation of statistical significance could be demonstrated between sleep disturbances and fatigue on one hand and bad psychological status due to stressful life event on the other hand. This result is in agreement with what has been previously reported. For instance, Ko et al., (2014) founded that $69.2 \%$ of Chinese mother's changes in sleeping habits as the most stressful life event. Song et al., (2010) reports that the process of acquiring the maternal role causes tension and stress.

\section{CONCLUSION:}

\section{Based on study findings, it can be concluded that:}

The great majority of the studied women had postnatal fatigue, and about more than two-thirds of them had sleep disturbance. Factors that were increased these 
problems including living with extended family and high crowding index. Receiving postnatal instructions seems to decrease both sleep and fatigue problems; both sleep and fatigue were decreased with staying one day only at the hospital. While help giving at home from women's sisters was decreasing women's sleep disturbances and fatigue compared with help from husband. There was a highly statistically significant positive correlation between sleep disturbance and fatigue.

\section{RECOMMENDATIONS:}

Based on the results of the present study, the following recommendations were suggested:

- Nurses caring for postnatal women should give more importance to instructing them regarding postnatal period with all the anticipated problems, and help them to cope with the difficulties encountered.

- Awareness program for women about who are at risk of developing postnatal fatigue and sleep disturbances, as mothers living in home environment not encouraging rest (living with extended families and high crowding index).

- Involvement of husband in program about instructions involved postnatal period as they are partners in this critical period; they should be trained for caring of the newborn so that they can help their wives to give them chance to rest and sleep.

- Sleep disturbances and fatigue need to be further investigated to be better understand the relationship between type of delivery\& maternal health outcome.

- Further research is proposed to assess the effect of nursing interventions to help women who have how to deal postnatal sleep disturbances and fatigue to cope with these problems.

\section{REFERENCES:}

Aigboje H.M, Osa-Afiana D.D. (2014): Sleep Deprivation: Effect on Mental Task Performance of Military Cadets: International Journal of Humanities and Social Science; 4(1): Pp202-208.

Ashrafinia F., Mirmohammadali M., Rajabi H., Kazemnejad A., Haghighi K.S. and Amelvalizadeh M. (2015): Effect of Pilates exercises on postpartum maternal fatigue: Singapore Med J;56 (3): Pp 169-173. 
Cheng C.Y and Li Q. (2008): Integrative review of research on general health status and prevalence of common physical health conditions of women after childbirth. Women's Health Issues; 18 (4): Pp 267-80.

Hall W., Stoll K., Hutton E., and Brown H. (2012): A prospective study of effects of psychological factors and sleep on obstetric interventions, mode of birth, and neonatal outcomes among low-risk British Columbian women: BMC Pregnancy and Childbirth;12 (78): Pp 2-10.

Huang K, Tao F, Liu L, and Wu X. (2011): Does delivery mode affect women's postpartum quality of life in rural China? Blackwell Publishing Ltd, Journal of Clinical Nursing 21, (11-12): Pp 1534-1543.

Kammerer M, Marks M.N, Pinard C, Taylor A, VonCastelberg B, Kunzli H, and Glover V, (2009): Symptoms associated with the DSM IV diagnosis of depression in pregnancy and postpartum. Arch Women's Mental Health; 12(3): Pp 135-141.

Karbandi S, Hosseini S.M, Masoudi R, Hosseini S.A, and Sadeghi F. (2016): Recognition of the efficacy of relaxation program on sleep quality of mothers with premature infants, Journal of Education and Health Promotion ;(4): Pp1-6.

Kilic M., Ozorhan E.Y., Çapik A., Agapinar S. and Özkan H. (2015): Comparison of Fatigue Levels of Postpartum Women According to the Birth Method, International Journal of Caring Sciences, 8 (1): Pp124-130.

Ko S-H, Chen C-H, Wang H-H, and Su Y-t (2014): Postpartum Women's Sleep Quality and Its Predictors in Taiwan: Journal of Nursing Scholarship; 46(2): Pp74-81.

Kuo, S.Y., Yang, Y.L., Kuo, P.C., Tseng, C.M. and Tzeng, Y.L. (2012): Trajectories of Depressive Symptoms and Fatigue among Postpartum Women, JOGNN, 41 (2): Pp216-226.

McBean A, and Montgomery-Downs H., (2015): Diurnal Fatigue Patterns, Sleep Timing, and Mental Health Outcomes among Healthy Postpartum Women. Biological Research for Nursing, 17(1): Pp29-39. 
Mohamed H.A., El Ngger N. and Lamadah S.M. (2012): Women' perspectives regarding the quality of postpartum nursing care in Ain Shams Maternity HospitalCairo, Egypt: Journal of American Science; 8 (2): Pp366-377.

Mohamed S. (2010): Sleep disturbances and fatigue among the postnatal women and influencing factors. Published, Faculty of nursing, Zagazing University, MSC, p14, Pp100-112.

Mousavi S.A, Mortazavi F, Chaman R, and Khosravi A. (2013): Quality of Life after Cesarean and Vaginal Delivery: Oman Medical Journal; 28 (4): Pp245-251.

Reeves W.C, Lloyd A, Vernon S.D, Klimas N, Jason L.A, Bleijenberg G, Evengard B, White P.D, Nisenbaum R, Unger E.R, and International Chronic Fatigue Syndrome Study Group., (2003): Identification of ambiguities in the 1994 chronic fatigue syndrome research case definition and syndrome research case definition and recommendations for resolution. BMC Health Services Research; 3:25.

Rezaei N, Azadi A, Zargousi R, Sadoughi Z, Tavalaee Z, and Rezayati M. (2016): Maternal Health-Related Quality of Life and Its Predicting Factors in the Postpartum Period in Iran; Hindawi Publishing Corporation Scientifica; Volume 2016:Pp1-7.

Roth T, Zammit G, Kushida C, Doghramji K, Mathias S.D, Wong J.M, and Buysse D.J (2002): A new Questionnaire to detect sleep disorders. Sleep Med.; 3(2): Pp99108.

Rowlands I.J and Redshaw M. (2012): Mode of birth and women's psychological and physical wellbeing in the postnatal period: BMC Pregnancy and Childbirth, 12,138: Pp1-11.

Rychnovsky J. (2011): The Relationship between Sleep Characteristics and Fatigue in Postpartum Women. Conference Sponsor: Sigma Theta Tau International.

Rychnovsky\& Hunter, (2009): The relationship between sleep characteristics and fatigue in healthy postpartum women: Women's Health Issues; 19(1): Pp38-44.

Sharkey K.M, Iko I.N, Machan J.T, Thompson-Westra J, and Pearlstein T.B (2016): Infant sleep and feeding patterns are associated with maternal sleep, stress, 
and depressed mood in women with a history of major depressive disorder (MDD): Arch Women's Mental Health; 19: Pp209-218.

Song J.-E., Chang S-B., Park S-M., Kim S, Nam C-M. (2010): Empirical test of an explanatory theory of postpartum fatigue in Korea. Journal of Advanced Nursing; 66 (12):Pp2627-2639.

Stein K.D, Jaceeobsen P.B, Blanchard C.M, and Thors C.(2004): Further Validation of the multidimensional fatigue symptom inventory-short form. J Pain Symptom Manage; 27(1): Pp14-23.

Unger E.R, Nisenbaum R, Moldofsky H, Cesta A, Sammut C, Reyesand M, Reeves W.C., (2004): Sleep assessment in a population-based study of chronic fatigue syndrome. BMC Neurology; 4:6doi:10.1186/1471-2377-4-6.

Ward S.L, Hisley S, Kennedy A.M. (2015): Maternal-Child Nursing Care, Optimizing outcomes for Mothers, Children\& Families.2nd edition, United States of America: Library of Congress Cataloging-in-Publication Data, P592.

White C.P, Bradley S.L, Neverve L, Stirewalt L, and Summers X., (2015): Does Maternal Fatigue Influence Maternal Verbal Control in a Stressful Parenting Task with Toddlers? Journal Child Family Stud; 24: Pp351-362. 
اضـطر ابـات النـوم والإر هــاق لــدي السيـدات مــا بـعد مـرحلـة الـــو لادة

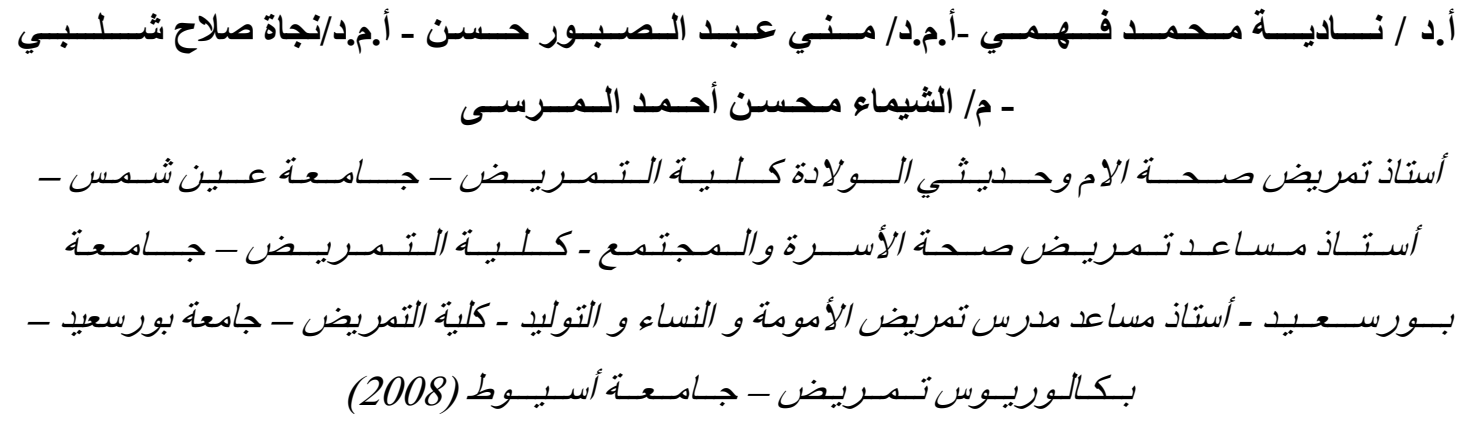

\section{الــــلاصــة}

النوم في مرحلة ما بعد الو لادة مهم نظر اللمشاكل المصاحبة مثل اضطر ابات الاستيقاظ، التعب و الاكتئاب مـا بعد الو لادة. الهـف من هذه الدر اسـة هو تحديد نسب اضطر ابات النوم و الار هـاق بين النسـاء مـا بعد الو لادة. ولتحقيق هذا الهدف فقد استخدمت در اسة وصفية لهذا البحث. لقد تم تنفيذ هذه الدر اسة في 6 مر اكز رعاية صدحة

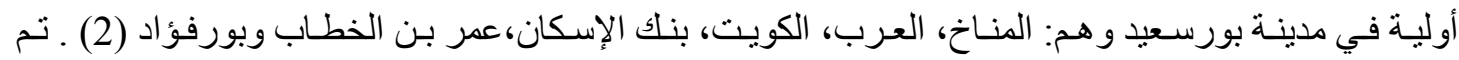
استخدام ثنلاث أدوات لجمع البيانـات: الاولي: (استمارة مقابلة): نموذج تجميع البيانـات الديمو غر افيـة، الثانيـة: مقياس التقييم العالمي للنوم، الثالثة: المقياس متعدد الأبعاد لأعراض الإرهاق. ولقد كثفت النتائج أن نسبة حدوث اضطر ابات النوم كانت (69.6\%)، بينمـا نسبة حدوث التعب كانت (93.8\%)، كمـا وجدت فروق ذات دلالـة

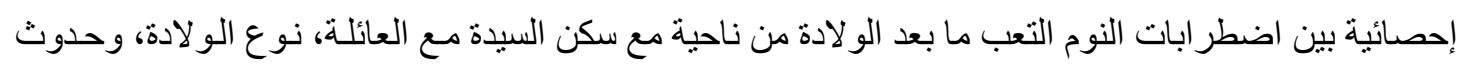

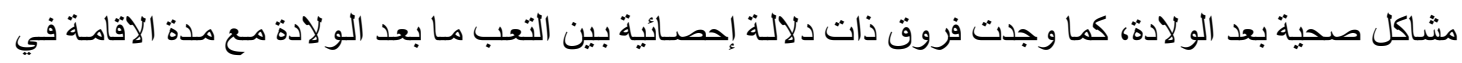

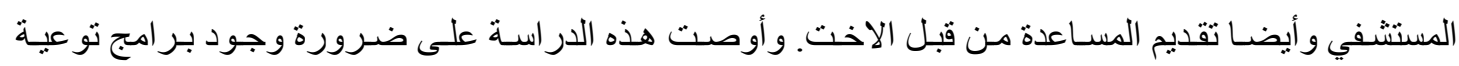

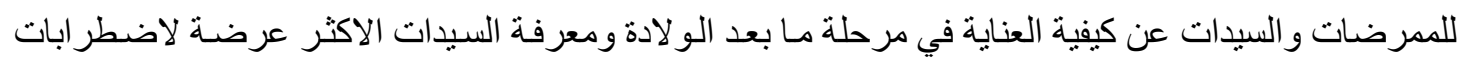
النوم و التعب في تللك المرحلة وكنلك معرفة كيفية التغلب علي تلك الصعوبات. 